\title{
Enzymatic Synthesis of Fatty Hydroxamic Acids from Palm Oil
}

\author{
Dedy Suhendra ${ }^{1 *, 2}$, W.M.Z. Wan Yunus ${ }^{1}$, Md. Jelas Haron ${ }^{1}$, Mahiran BASRI ${ }^{1}$, \\ and Sidik SILONG ${ }^{1}$ \\ ${ }^{l}$ Department of Chemistry, Faculty of Science and Environmental Studies Universiti Putra Malaysia \\ (43400 UPM Serdang Selangor, MALAYSIA) \\ ${ }^{2}$ Department of Chemistry, FKIP Universitas Mataram NTB Indonesia
}

(J1. Majapahit 62 Mataram 83125)

Edited by T. Nakahara, AIST, Tsukuba, and accepted August 12, 2004 (received for review June 24, 2004)

\begin{abstract}
Fatty hydroxamic acids (FHA) have been successfully synthesized from palm oils by a one-step lipase catalyzed reaction. The use of immobilized lipase as the catalyst for the preparation reaction provides an easy isolation of the enzyme from the products and other components in the reaction mixture. In addition, it also allows the reaction to be carried out under mild conditions, which reduces the reaction's side products. The percentages of conversion of commercial palm olein (CPOn), RBD (refined, bleached and deodorized) palm olein (POn), RBD palm oil (PO), RBD palm stearin (PS) and RBD palm kernel olein (PKOn) into their fatty hydroxamic acids are 89, 79, 77, 90 and 98, respectively.
\end{abstract}

Key words: enzymatic synthesis, fatty hydroxamic acid, lipase, palm oil

\section{Introduction}

Hydroxamic acids ( $N$-hydroxy carboxylic amides) may be regarded as derivatives of both hydroxylamine and carboxylic acids. The general formula of hydroxamic acid is R-CO-NHOH. In recent years, hydroxamic acids derivatives have received a lot of attention due to their biological activity as growth factors, food additives, antibiotics, antifungal agents, cell division factor and metal chelators (1), enzyme inhibitors (2), matrix metalloproteinase (MMP) inhibitor (3-5) and tumor inhibitors (6). Their complexes with various metal ions have been used for analytical chemistry as reagents for gravimetric and spectrometric metal determination (7), as collector for rare earth mineral (8), and for metal ions extraction from aqueous media (9). Simple and polymeric hydroxamic acids have also been extensively investigated for several successful analytical separations of metal ions. Besides their ability to form complex with metal ions, long-chain hydroxamic acids, by modi- fication of the terminal $\mathrm{OH}$ group, are of considerable interest as efficient surfactants in the detergent industry (10).

Hydroxamic acids, in general, have been synthesized by adopting Blatt's procedure (11). In this method, the reaction of an alkyl or aryl ester (RCOOEt) with hydroxylamine in the presence of alkali and the free acid is obtained by the addition of acid in the appropriate quantity in cold solution. However, this chemical method, which is in alkali system, could evoke decomposition or degradation of the desired products due to presence of double bond.

An enzymatic route for the synthesis of hydroxamic acid, with the inherent advantages of selectivity, mild reaction conditions and enantioselection, is of considerable synthetic interest. The synthesis of alkanohyroxamic acids ( $N$-acyl hydroxylamines) by Rhizomucor miehei lipase-catalyzed hydroxylaminolysis of fatty acids and soybean methyl ester was reported (12). Later, Candida parapsilopsis was also found to mediate

\footnotetext{
${ }^{*}$ Correspondence to: Dedy SuHENDRA, Department of Chemistry, Faculty of Science and Environmental Studies Universiti Putra Malaysia 43400 UPM Serdang Selangor Malaysia

E-mail: dedysuhendra@hotmail.com; fi_hendra@yahoo.com
} 
this reaction $(13,14)$.

In this work we have investigated the use of an immobilized lipase as biocatalyst for hydroxylaminolysis of palm oil. This work focuses on the lipase-catalyzed synthesis of FHA from commercial palm olein. Our literature search indicates that this is first report of FHA synthesis directly from oil. The advantages of this method include ease of preparation reaction and product isolation, and commercially available of reactants and catalyst.

\section{Materials and Methods}

\subsection{Materials}

All the chemicals used were of analytical grade: hydroxylamine hydrochloride and sodium hydroxide were from Fluka (Switzerland). Methanol and hexane were from T.J. Beaker (USA). The immobilized lipase used was the product from Novo Nordisk (Denmark). RBD palm oil, RBD palm olein, RBD palm Stearin and RBD palm kernel olein were supplied by Southern Edible Oil Industry (M) Sdn. Bhd. (Malaysia). Meanwhile, the commercial palm olein was obtained from Ngo Chew Hong Oils and Fats (M) Sdn. Bhd. Malaysia.

\subsection{Hydroxylaminolysis}

The reaction was carried out by reacting a required amount of commercial palm olein with hydroxylamine in the present Lypozyme in a $100 \mathrm{~mL}$ stoppered flask. The mixture was incubated in water shaker batch at 100 rpm. The FHA formed in water-hexane interface was then separated from the water and the lipase by filtration. To obtain the solid FHA, the hexane fraction was cooled in a refrigerator $\left(<-5^{\circ} \mathrm{C}\right)$ for $5 \mathrm{~h}$ and then filtered and washed by hexane for several times and dried in vacuum desiccator over phosphorous pentoxide for $24 \mathrm{~h}$.

\subsection{Characterization}

Qualitative analysis of hydroxamic acid groups on FHA was carried out by observing the colored complex formed after the methanolic solution of the FHA reacted with iron (III), copper (II) and vanadium (V) in a dilute hydrochloric acid solution. The amount of the hydroxamic acid group was estimated based on nitrogen content of the dry FHA determined by Elemental analyzer model 932 (LECO, USA). FTIR spectra of the products were recorded with Fourier Transform
Infrared Spectrophotometer (Perkin Elmer FTIR-Spectrum $\mathrm{BX}$, USA) using $\mathrm{KBr}$ pellets. The High-Performance Liquid Chromathography (HPLC) analyses were performed according to the procedure of Gutnikov and Streng (15) with modifications using liquid chromatograph (Waters HPLC, USA) equipped with Waters Delta-600 pump, Waters 600-controller, Waters-2487 Dual $\lambda$ Absorbance Detector and Shimadzu CTO-6A column oven. Separations were performed on a reversed-phase column $(3.9 \times 150 \mathrm{~mm})$ obtained from Alltech Assoc. (Deerfield, IL, USA) packed with Nucleosil $\mathrm{C}_{18}, 5 \mu \mathrm{m}$ particle size. Column temperature was maintained at $40^{\circ} \mathrm{C}$. The absorbance was monitored at $213 \mathrm{~nm}$, and the detector signals were fed to a Waters-2487 integrator. Samples were injected via a Waters-600 rotary injector valve fitted with a $10 \mu \mathrm{l}$ loop. Analyses were performed using a methanol-aqueous buffer solvent system (80:20) at a flow rate 1.0 $\mathrm{mL} / \mathrm{min}$. The aqueous buffer was prepared as $20 \mathrm{mM}$ sodium dihydrogenphosphate adjusted to $\mathrm{pH} 3$ with concentrated phosphoric acid. A $125-\mu 1$ volume of $1 \%$ $(\mathrm{w} / \mathrm{w})$ sodium nitrate per liter was added to match the absorbance of methanol at $213 \mathrm{~nm}$.

\section{Results and Discussion}

\subsection{Effect of Reaction Period}

The time course is a good indicator of enzyme performance and reaction progress. It can pinpoint the shortest or adequate time necessary to obtain good yields and minimize process expenses (16). The results (Fig. 1) show that enzymatic reaction proceeded rapidly in the first $30 \mathrm{~h}$. Although the maximum yield is obtained at the reaction period at around $50 \mathrm{~h}$, the rate of the reaction after $30 \mathrm{~h}$ is small. The decrease in the reaction rate may be due to; (i) some mass-transfer limitations, which inevitably arise in a reaction mixture containing a high proportion of solid product, and (ii) the reaction reaches the equilibrium state where the rate of forward reaction was equal to the backward reaction. However, this result is faster compared with the result of Hacking et al., (2000) (17), which shows that the biosynthesis of octanohydroxamic acid reaction was reaches the maximum conversion at $36 \mathrm{~h}$.

\section{$3 \cdot 2$ Effect of Organic Solvent}

Two important properties of a solvent to be used in biocatalysis are its ability to solubilize the substrate and 


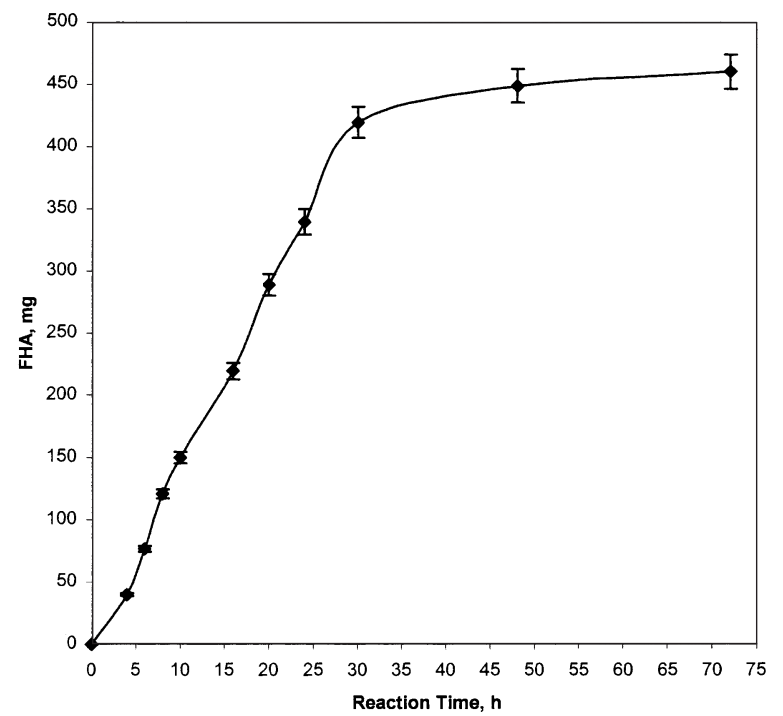

Fig. 1 Effect of Reaction Period on Hydroxylaminolysis of FHA. Reaction conditions: $\mathrm{NH}_{2} \mathrm{OH} 10 \mathrm{mmol}$; commercial palm olein $2 \mathrm{~g}$; Lipozyme $0.05 \mathrm{~g}$; hexane volume $15 \mathrm{~mL}$; temperature $40^{\circ} \mathrm{C}$; shaking rate $150 \mathrm{rpm}$.

the products of the reaction, and its influence on enzyme activity and stability. In addition, a solvent should also have the ability of portioning the substrates and products into different phases (18). Several organic solvent, which are widely used as solvent for palm oil were investigated for the study of the effect of organic solvent on the hydroxylaminolysis of palm oil. The results (Table 1) show that hexane is the best solvent for hydroxylaminolysis of the commercial palm olein. Therefore, hexane was used as solvent in the subsequent experiments.

\section{3·3 Effect Amount of Enzyme}

From an applied point of view, the substrate concentration should be as high as possible to obtain a higher degree of yield. Simultaneously, the amount of enzyme used should be as low as possible to obtain the desired result. In terms of production cost, the impact of the amount of lipase used is crucial.

Figure 2 shows that the reaction yield increases as the ratio of lipase: substrate is increased. The highest production of FHA is obtained when the ratio of lipase: substrate is $29.5 \mathrm{mg}$ to $1 \mathrm{mmol}$. Further increase of lipase to substrate ratio does not significantly increase the yield. This behavior of leveling off of the reaction at higher enzyme concentrations can be explained by con-
Table 1 Effect of Solvent on Synthesis of FHA.

\begin{tabular}{|c|c|}
\hline Solvent & Yield (mg) \\
\hline Heptane & 366 \\
\hline Hexane & 270 \\
\hline Cyclohexane & 201 \\
\hline Chloroform & 86 \\
\hline
\end{tabular}

Reaction conditions: $\mathrm{NH}_{2} \mathrm{OH} 10 \mathrm{mmol}$; commercial palm olein $2 \mathrm{~g}$; Lipase $0.05 \mathrm{~g}$; hexane volume $15 \mathrm{~mL}$; temperature $40^{\circ} \mathrm{C}$; shaking rate $150 \mathrm{rpm}$; reaction period $24 \mathrm{~h}$.

sidering that the active sites of the enzyme molecules present in excess would not be exposed to the substrates and remain inside the bulk of enzyme particles without contributing significantly to the reaction (19).

\section{$3 \cdot 4$ Effect of Concentration of Hydroxyl- amine}

The maximum mole ratio of substrates used in the preparation reaction is a challenge to be met in industrial implementation of any reaction (20). Figure 3 shows that the yield is highest when the ratio of the hydroxylamine and the commercial palm olein was at $6 \mathrm{mmol}$ to $1 \mathrm{mmol}$. This result is in agreement with Servat et al.

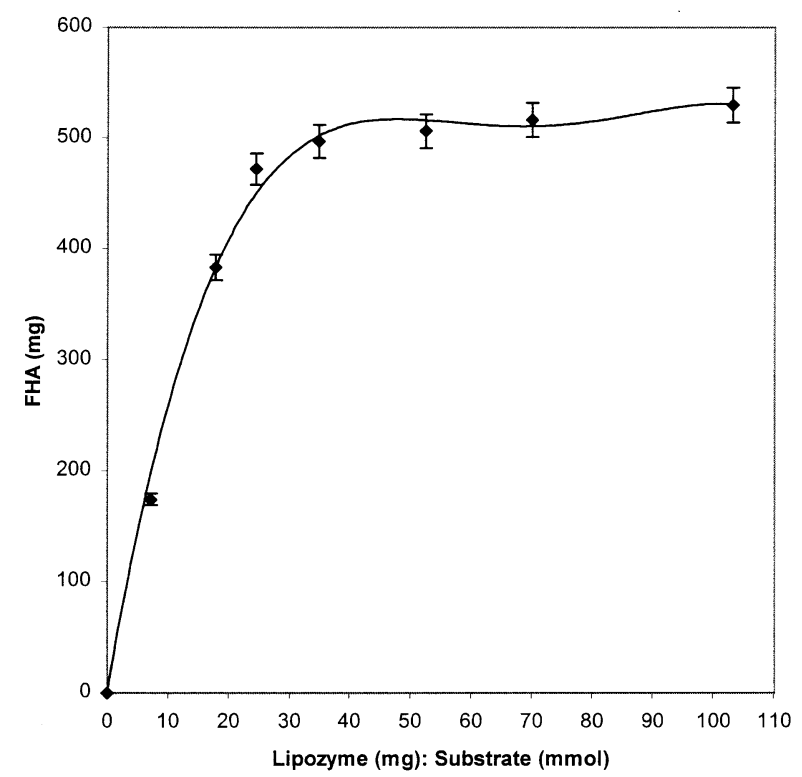

Fig. 2 Effect of Amount of Lipase on Biosynthesis of FHA; Reaction conditions: substrate (commercial palm olein) $2 \mathrm{~g}$, temperature $40^{\circ} \mathrm{C}$, hexane volume $15 \mathrm{~mL}$, shaking rate $150 \mathrm{rpm}$, reaction period $24 \mathrm{~h}$. 
(12) that shows the reaction yield increases with the increase in the concentration of hydroxylamine. However, increasing further the concentration of hydroxylamine decreases the reaction yield. This phenomenon was in agreement with the results of Vaysse et al. (14), which shows that high concentrations of hydroxylamine were inhibitory to the reaction.

\section{$3 \cdot 5$ Scaling up the Reaction}

The reactions were scaled-up (50 times) by using the optimum condition presented in Table 2. The percentages of conversion of hydroxylaminolysis of palm oils are presented in Fig. 4. The Figure shows that there is slight difference in the reaction yield of hydroxylaminolysis among various products of palm oil with the percentages of conversion being in the range of 77 98.

\subsection{Characterization of FHA}

Complexes of the FHA with vanadium, iron (III) and copper (II) are purple, dark red and green, respectively. These are the common color of the complexes observed when these metal ions are reacted with hydroxamic acids (21). FTIR spectrum of substrate (commercial palm olein, Fig. 5a) shows the characteristic absorption bands at $2848 \mathrm{~cm}^{-1}$ and $2916 \mathrm{~cm}^{-1}$, which correspond to

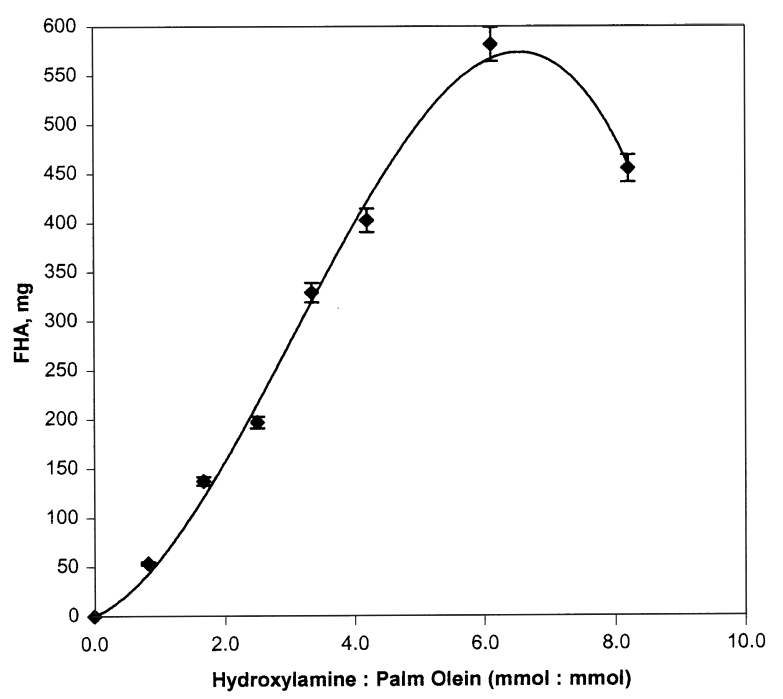

Fig. 3 Effect of Concentration of Hydroxylamine on Biosynthesis of FHA; Reaction conditions: substrate (commercial palm olein) $2 \mathrm{~g}$, Lipozyme $0.05 \mathrm{~g}$, hexane volume $15 \mathrm{~mL}$, shaking rate 150 $\mathrm{rpm}$, reaction period $24 \mathrm{~h}$
Table 2 Optimum Condition of Hydroxylaminolysis of Palm Oils.

\begin{tabular}{|c|c|}
\hline Parameters & Condition \\
\hline Lipase & Lipozyme \\
\hline Solvent & Hexane \\
\hline Reaction Period & $30 \mathrm{~h}$ \\
\hline Temperature & $30^{\circ} \mathrm{C}$ \\
\hline Ratio Lipozyme (mg): Substrate (mmol) & 29.5: 1 \\
\hline Ratio Hydroxylamine (mmol): Substrate (mmol) & 6: 1 \\
\hline
\end{tabular}

C-H stretching of long alkyl chain. These absorption bands were supported by peak at $1452 \mathrm{~cm}^{-1}$ that corresponds to $\mathrm{C}-\mathrm{H}$ bending. Additional characteristic absorption band of palm oil appear at $1740 \mathrm{~cm}^{-1}$ corresponding to $\mathrm{C}=\mathrm{O}$ stretching. FTIR spectrum of the product (Fig. 5b) shows the characteristic absorption bands of hydroxamic acid at $3426 \mathrm{~cm}^{-1}$ and $3264 \mathrm{~cm}^{-1}$, which corresponds to $\mathrm{N}-\mathrm{H}$ and $\mathrm{OH}$ stretching respectively. These absorption bands are typical bands for amide (14). Additional characteristic absorption bands of hydroxamic acid appear at $1662 \mathrm{~cm}^{-1}$ that correspond to $\mathrm{C}=\mathrm{O}$ in secondary amide. Fig. $4 \mathrm{~b}$ also shows the characteristic absorption bands at $2848 \mathrm{~cm}^{-1}$ and 2916 $\mathrm{cm}^{-1}$, which correspond to C-H stretching of long alkyl chain. Unsaturated of FHA was shown at 3010 - 3095 $\mathrm{cm}^{-1}$ that corresponds to $\mathrm{C}-\mathrm{H}$ alkenes $(\mathrm{C}=\mathrm{C}-\mathrm{H})$ and $1610-1680 \mathrm{~cm}^{-1}$ that corresponds to alkenes $(\mathrm{C}=\mathrm{C})$

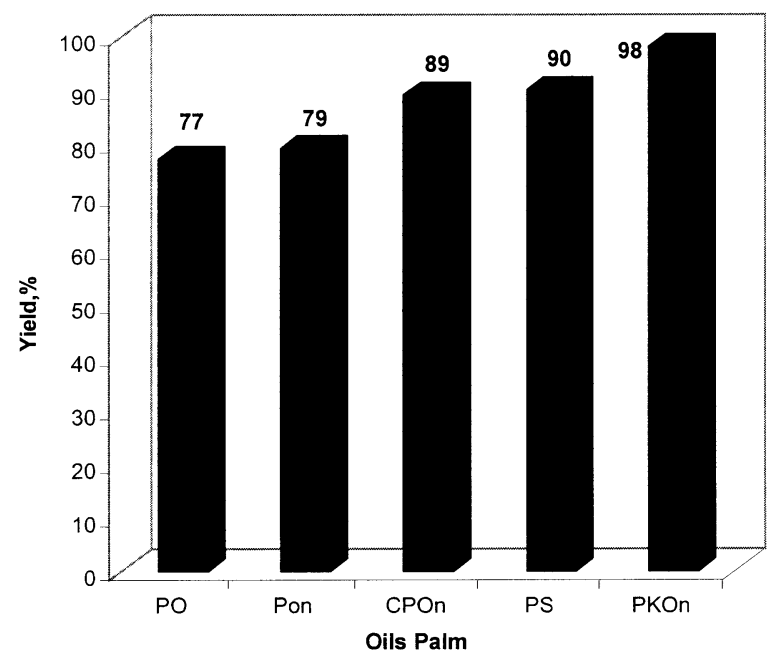

Fig. 4 Reaction Yield of Hydroxylaminolysis of Palm Oils. Yield $(\%)=(\mathrm{mmol}$ product $/ \mathrm{mmol}$ fatty acid in oil) $x 100$. 


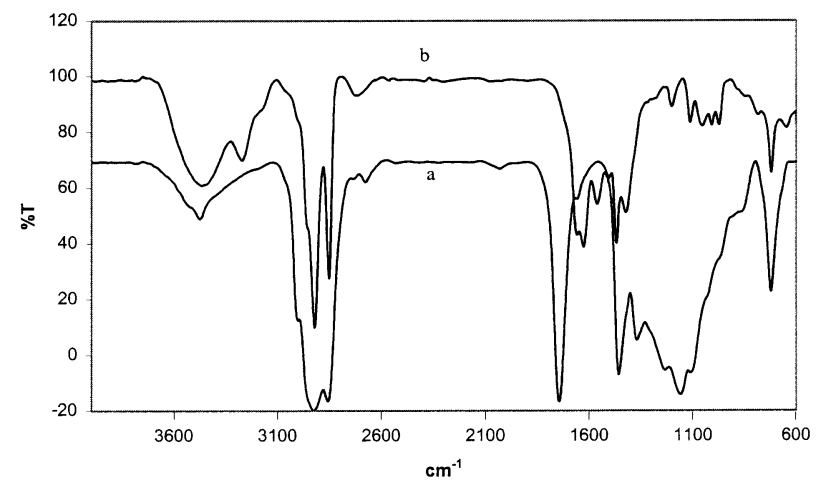

Fig. 5 FTIR Spectrum of (a) Commercial Palm Olein and (b) FHA from Commercial Palm Olein.

(22). Both qualitative tests support that the FHA is successfully produced from the commercial palm olein. The nitrogen content of the dry FHA analyzed by the elemental analysis is found to be $4.93 \%$. This indicates that there was $3.52 \mathrm{mmol} / \mathrm{g}$ of hydroxamic acid groups in one gram of the FHA. HPLC analyses of the product shows that the FHA was actually a mixture of lauryl-, myristyl-, palmityl-, stearyl-, oleyl- and linoleylhydroxamic acid, as palm olein consist of lauric$(0.5 \%)$, myristic- $(1.2 \%)$, palmitic- $(38.5 \%)$, stearic(4.4\%), oleic-(41\%) and linoleic acids (12.1\%) (23).

\section{Conclusion}

The enzymatic synthesis method of fatty hydroxamic acids (FHA) described in this paper is an effective method for preparing FHA from palm oil and suggested that it could be applicable to a large-scale production of FHA. The method employed offers technical simplicity, easy isolation of the enzyme from the products and other components in the reaction mixture. Moreover, it also allows to be carried out under mild conditions, which reduce unwanted products from side-reactions. The percentages of conversion of commercial palm olein, RBD palm olein, RBD palm oil, RBD palm stearin and RBD palm kernel olein into their fatty hydroxamic acids are $89,79,77,90$ and 98 , respectively.

\section{References}

1. B. KURZAK, A. KOZLOWSKI and F. FARKAS, Hydroxamic and Amino Hydroxamic Acids and Their Complexes with Metal
Ions, Coordination Chemistry Reviews, Vol. 114, 169-200 (1992).

2. S.M. DANKWARDT, R.L. MARTIN, C.S. CHAN, H.E. VAN WART, K.A.M. WALKER, N.G. DELAET and L.A. ROBINSON, Amino Acid Derived Sulfonamide Hydroxamates as Inhibitors of Procollagen C-Proteinase: Solid-Phase Synthesis of Ornithine Analogues, Bioorganic \& Medicinal Chemistry letters, Vol. 11, 1465-1468 (2001).

3. S. HANESSIAN, N. MOITESSIER and L.D. CANTIN, Design and Synthesis of MMP Inhibitors Using N-Arylsulfonylaziridine Hydroxamic Acids as Constrained Scaffolds, Tetrahedron, Vol. 57, 6885-6900 (2001).

4. A.D. BAXTER, R. BHOGAL, J. BIRD, J.F. KEILY, D.T. MANALLACK, J.G. MONTANA, D.A. OWEN, W.R. PITT, R.J. WATSON and R.E. WILLS, Arylsulphonyl Hydroxamic Acids; Potent and Selective Matrix Metalloproteinase Inhibitors, Bioorganic \& Medicinal Chemistry Letters, Vol. 11, 1465-1468 (2001).

5. R.J. WATSON, D. BATTY, A.D. BAXTER, D.R. HANNAH, D.A. OWEN and J.G. MONTANA, An Enantioselective Synthesis of Sulphonamide Hydroxamic Acids as Matrix Metalloproteinase Inhibitors, Tetrahedron Letters, Vol. 43, 683-685 (2002).

6. J. HOLMES, K. MAST, P. MARCOTTE, I. ELMORE, J. LI, L. PEASE, K. GLASER, D. MORGAN, M. MICHAELIDES and S. DAVIDSEN, Discovery of Hydroxamic Acid Inhibitors of Tumor Necrosis Factor- $\alpha$ Converting Enzyme, Bioorganic \& Medicinal Chemistry Letters, Vol. 11, 2907-2910 (2001).

7. Y.K. AGRAWAL and S.A. PATEL, Hydroxamic Acids: Reagents for The Solvent Extraction and Spectrophotometric Determination of Metals, Rev. Analytical Chemistry, Vol. 4, 237 276 (1980).

8. Y.K. AGRAWAL and H. KAUR, Poly ( $\beta$-styryl) Hydroxamic Acids: Synthesis and Ion Exchange Separation of Rear Earths, Reactive \& Functional Polymers, Vol. 39, 155-164 (1999).

9. Y.K. AGRAWAL, P. SHRIVASTAV and S.K. MENON, Solvent Extraction, Separation of Uranium (VI) with Crown Ether, Separation and Purification Technology, Vol. 200, 177-183 (2000).

10. A. MASUYAMA, K.I. AKIYAMA and M. OKAHARA, Surface Active Hydroxamic Acids. I. Preparation and Properties of Long-Chain Alkyl[oligo(oxyethylene)] oxymethylenehydroxamic acids, J. Am. Oil Chem. Soc., Vol. 64, 764-768 (1987).

11. A. BLATT, Organic Synthesis, Collective Vol. 2, John Wiley, 67 (1963).

12. F. SERVAT, D. MONTET, M. PINA, P. GAZLY, A. ARNAUD, H. LEDON, L. MARCAU and J. GRAILLIE, Synthesis of Fatty Hydroxamic Acids Catalyzed by The Lipase of Mucor Meihei, J. Am. Oil Chem. Soc., Vol. 67 (10), 646-649 (1990).

13. D. FOURNAND, A. ARNAUD, P. GALZY, F. BIGEY and R. RATOMAHENINA, Biocatalyst Improvement for The Production of Short Chain Hydroxamic Acids, Enzyme and Microbial Technology, Vol. 20, 424-431 (1997).

14. L. VAYSSE, E. DUBREUEQ, J.L. PIRAT and P. GALZY, Fatty Hydroxamic Acid Biosynthesis in Aqoeous Medium in The Presence of The Lipase-Acyltransferase from Candida parap- 
silosis, Journal of Biotechnology, Vol. 53, 41-46 (1997).

15. G. GUTNIKOV and J.R. STRENG, Rapid High Performance Liquid Chromatographic Determination of Fatty Acid Profiles of Lipids by Conversion to Their Hydroxamic Acids, Journal of Chromatography, Vol. 587, 292-296 (1991).

16. L.N. YEE, C.C. AKOH and R.S. PHILIPS, Lipase PS-Catalyzed Transesterification of Citronellyl Butyrate and Geranyl Caproate: Effect of Reaction Parameters, J. Am. Oil Chem. Soc., Vol. 74, 255-259 (1997).

17. M.A.P.J. HACKING, H. AKKUS, VAN F. RANTWIJK and R.A. SHELDON, Lipase and Esterase-Catalyzed Acylation of Hetero-Substituted Nitrogen Nucleophiles in Water and Organic Solvents, Biotechnol. Bioeng., Vol. 68, 84-91 (2000).

18. M. RESLOW, P. ADLERCREUTZ and B. MATTIASON, On The Important of The Support Material for Bioorganic Synthesis: Influence of Water Partition Between Solvent, Enzyme and Solid Support in Water-Polar Reaction Media, Eur. J. Biochem.,
Vol. 177, 313-318 (1988).

19. S.H. KRISHNA, S. DIVAKAR, S.G. PRAPULLA and N.G. KARANTH, Enzymatic Synthesis of Isoamyl Acetate Using Immobilized Lipase from Rhizomucor miehei, Journal of Biotechnology, Vol. 87, 193-201 (2001).

20. J.A. ARCOS, M. BARNABE and C. OTERO, Quantitative Enzymatic Production of 6-O-Acylglucose Esters, Biotechnol. Bioeng., Vol. 57, 505-509 (1998).

21. M.J. HARON, W.M.Z. WAN YUNUS, M.Z. DESA and A. KASSIM, Synthesis and Properties of Poly(hydroxamic acid) from Crosslinked Poly(methacrylate), Talanta, Vol. 41, 805-807 (1994)

22. D.A. SKOOG, F.J. HOLLER and T.A. NIEMAN, Principles of Instrumental Analysis. 5th edn., USA: Thomson Learning, Inc. (1998).

23. B.K. TAN and C.H. OH, PORIM Technology No. 3 Kuala Lumpur, Malaysia (1981). 